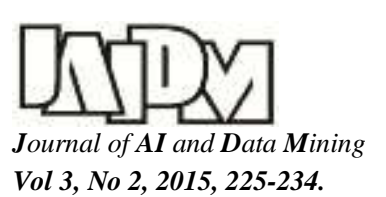

10.5829/idosi.JAIDM.2015.03.02.12

\title{
Improving the performance of UPQC under unbalanced and distortional load conditions: A new control method
}

\author{
R. Ghanizadeh* and M. Ebadian \\ Department of Electrical \& Computer Engineering, University of Birjand, Birjand, Iran. \\ Received 24 April 2014; Accepted 21 June 2015 \\ *Corresponding author: $r$ _ghanizadeh@birjand.ac.ir(R. Ghanizadeh).
}

\begin{abstract}
This paper presents a new control method for a three-phase four-wire Unified Power Quality Conditioner (UPQC) to deal with the problems of power quality under distortional and unbalanced load conditions. The proposed control approach is the combination of instantaneous power theory and Synchronous Reference Frame (SRF) theory which is optimized by using a self-tuning filter (STF) and without using load or filter currents measurement. In this approach, load and source voltages are used to generate the reference voltages of series active power filter (APF) and source currents are used to generate the reference currents of shunt APF. Therefore, the number of current measurements is reduced and system performance is improved. The performance of proposed control system is tested for cases of power factor correction, reducing source neutral current, load balancing and current and voltage harmonics in a three-phase four-wire system for distortional and unbalanced loads. Results obtained through MATLAB/SIMULINK software show the effectiveness of proposed control technique in comparison to the conventional p-q method.
\end{abstract}

Keywords: Power Quality, Unified Power Quality Conditioner, Voltage Harmonic Mitigation, Current Harmonic Mitigation, Source Neutral Current Mitigation.

\section{Introduction}

Among the main problems of power quality in the three-phase four-wire systems are the current harmonics, load unbalance, exceeding neutral current, voltage harmonic, voltage sag and voltage swell. Poor power quality causes low power factor, low efficiency and overheating of transformers and so on [1]. Furthermore, in distribution systems, the total load of system is rarely balanced, and this increases the neutral current in three-phase four-wire systems. Since the fundamental component of current and current components of higher frequencies exist in the neutral current, their passing through the neutral wire causes it to overheat [2]. By using more complicated and more advanced softwares and hardwares in control systems, power quality has become one of the most important issues for electronic engineers. Thus, to deal with the problem of power quality, numerous standards have been presented by various standard organizations e.g. IEEE519 standard. Ideally, the current and voltage waveforms are in phase, power factor is equal to unity and consumed reactive power is equal to zero. Under such conditions, active power could be transmitted with maximum efficiency [3]. Passive filters were used in the past to deal with power quality problems. However, their limitations including fixed compensation, possibility of occurrence of resonance with the source impedance and problems of tuning passive filter parameters caused the research on active filters and hybrid filters to start [4-6]. UPQC is one of the best solutions for simultaneous compensation of voltage and current problems [6,7]. UPQC was introduced for the first time in 1998 by Fujita and Akagi [7]. The structure of UPQC is similar to that of unified power flow controller (UPFC) used in transmission systems and its main goal is to control power flow in the fundamental frequency [8], whereas UPQC is used in distribution systems for performing duties of series and shunt APFs simultaneously. On the other hand, distribution network may have DC components or harmonics 
and may be unbalanced. Therefore, UPQC must carry out parallel and series compensation under such conditions [9]. The shunt and series APFs of UPQC are linked to each other by a dc-link. In UPQC, unlike UPFC, the series APF is connected to the source side and the shunt APF is connected to the load side. The shunt APF is used to compensate current distortions and to supply load reactive power [7]. Thus, the shunt APF of UPQC acts as a current source which injects the compensation current into the network. The series APF is used to compensate voltage fluctuations and so it can act as voltage source which injects the compensation voltage into the network through a series transformer.

In the past few years, several control strategies have been presented in literature for determining the voltage and current reference signals. Some of the most common strategies include p-q-r theory [10], improved single-phase p-q theory [11], synchronous reference frame (SRF) theory [12], symmetric component transformation [13], I $\cos \varphi$ theory $[14,15]$ and some other innovative control methods[16,17]. In [18], the one-cycle control approach (without calculating the reference) is used for controlling a three-phase four-wire UPQC. Among the these control methods, the most important and common control methods are $\mathrm{p}-\mathrm{q}$ and SRF theories and so far some research have been done to modify these two control theory [19-22]. However, these two strategies based on balanced three phase systems can be used for single phase systems [23,24]. In Some research, these two control methods combined for better performance of UPQC $[25,26]$.

One of the important parts in both these strategies is PLL determining automatically the system frequency and the phase angle of fundamental positive-sequence component of three phase generic input signal [27]. In order to improve performance of UPQC under distorted and unbalanced voltage waveforms, some research have been done to modify PLL circuit $[19,20]$. As the application of artificial neural network and fuzzy inference systems is growing in power electronics, an ANN-based controller is designed for current control of shunt active filter [28]. The performance of fuzzy logic controller and ANN controller is compared [29].

In this paper, the proposed control method which is the combination of instantaneous power theory and synchronous reference frame (SRF) theory is optimized by using a STF and without using load or filter currents measurement. The performance of proposed system is tested by using MATLAB/SIMULINK software in cases such as power factor correction, reducing source neutral current, load balancing and reducing current and voltage harmonics in a three-phase four-wire system for distortional and unbalanced loads. Results obtained from simulation show the power and effectiveness of proposed control method in comparison to the conventional p-q method.

\section{UPQC}

The UPQC improves power quality, because of its capability in removing harmonics and simultaneous compensation of voltage and current. Almost all papers about UPQC show that it could be used for solving all the power quality problems. Figure 1 shows the basic structure of UPQC consisting of shunt and series APFs. The shunt APF is used for absorbing current harmonics, compensating reactive power and regulating dc-link voltage. The main purpose of using series APF is removing voltage harmonics of the source. Furthermore, series APF is capable of compensating voltage unbalance and compensating harmonics at the point of common coupling in consumer side [28].

\section{Proposed control method}

\subsection{STF}

Hong-Sock studied integral in the synchronous reference frame and showed that:

$V_{x y}(t)=e^{j \omega t} \int e^{-j \omega t} U_{x y}(t) d t$

where, $\mathrm{U}_{\mathrm{xy}}$ and $\mathrm{V}_{\mathrm{xy}}$ are instantaneous signals respectively before and after the integration in the synchronous reference frame [30]. Applying the Laplace transform on (1), the equation of the transfer function $H(s)$ is expressed as:

$H(s)=\frac{V_{x y}(s)}{U_{x y}(s)}=\frac{s+j \omega}{s^{2}+\omega^{2}}$

In order to obtain self-tuning filter (STF) with a cutoff frequency from the transfer function $\mathrm{H}(\mathrm{s})$, a constant parameter $\mathrm{k}$ is introduced [31]. Thus, by the use of parameter $\mathrm{k}$, a function $\mathrm{H}(\mathrm{s})$ can be written as follows:

$H(s)=\frac{V_{x y}(s)}{U_{x y}(s)}=\frac{k(s+k)+j \omega_{n}}{(s+k)^{2}+\omega_{n}{ }^{2}}$

By adding a constant parameter $\mathrm{k}$ to $\mathrm{H}(\mathrm{s})$, the amplitude of the transfer function is limited and equal to the amplitude of frequency component $\left(\omega_{\mathrm{n}}\right)$. In addition, the phase delay is zero for cutoff frequency. By replacing the input signals $U_{x y}(s)$ by $\mathrm{x}_{\alpha \beta}(\mathrm{s})$ and the output signals $\mathrm{V}_{\mathrm{xy}}(\mathrm{s})$ by $\mathrm{x}_{\alpha \beta}(\mathrm{s})$, the following expressions can be obtained:

$\hat{\mathbf{x}}_{\alpha}=\left(\frac{\mathbf{k}}{\mathbf{s}}\left[\mathbf{x}_{\alpha}(\mathbf{s})-\hat{\mathbf{x}}_{\alpha}(\mathbf{s})\right]-\frac{\omega_{\mathrm{n}}}{\mathbf{s}} \cdot \hat{\mathbf{x}}_{\beta}(\mathbf{s})\right)$ 
$\hat{\mathbf{x}}_{\beta}=\left(\frac{\mathbf{k}}{\mathrm{s}}\left[\mathrm{x}_{\beta}(\mathrm{s})-\hat{\mathbf{x}}_{\beta}(\mathrm{s})\right]-\frac{\omega_{\mathrm{n}}}{\mathrm{s}} \cdot \hat{\mathbf{x}}_{\alpha}(\mathrm{s})\right)$

where, $\boldsymbol{\omega}_{\mathbf{n}}$ is desired output frequency, and $\mathrm{k}$ is the filter gain. The higher the value of $k$, the higher the accuracy of extracting the desirable component is. Also, when the value of $k$ decreases, the transient duration increases. $\mathrm{x}_{\alpha \beta}(\mathrm{s})$, and $\hat{x}_{\alpha \beta}(s)$ may also be either voltage or current signals, respectively before and after filtering. Therefore, by using a STF, the fundamental component of distortional signals can be obtained without changing the amplitude and phase delay. According to (4) and (5), block diagram of STF is shown in figure 2 [31].

Figure 3 shows the frequency response of the STF versus different values of the parameter $k$ for $\mathrm{fc}=50 \mathrm{~Hz}$. At $50 \mathrm{~Hz}$, the phase angle of bode diagram is null, which means that the two input and output signals are in phase either $\mathrm{k}$. Also the phase shift for the other frequencies is shown. On the other hand, it is observed from figure 3 showing that $|\mathrm{H}(\mathrm{s})|=0 \mathrm{~dB}$ at $\mathrm{f}_{\mathrm{c}}=50 \mathrm{~Hz}$. The rate of amplitude changes for the other frequencies is shown in figure 3 .

One of the feature of STF is that despite extreme unbalance between two input signals, the STF will create always two equal magnitude sine-waves according to following equation:

$$
\frac{\mathbf{x}_{\alpha}(\mathbf{s})+\mathbf{x}_{\beta}(\mathbf{s})}{2}=\hat{\mathbf{x}}_{\alpha}(\mathbf{s})=\hat{\mathbf{x}}_{\beta}(\mathbf{s})
$$

This feature is a disadvantage of STF for generating reference load voltages under unbalance voltage condition. To overcome this problem, d-q theory is used for control of series APF.

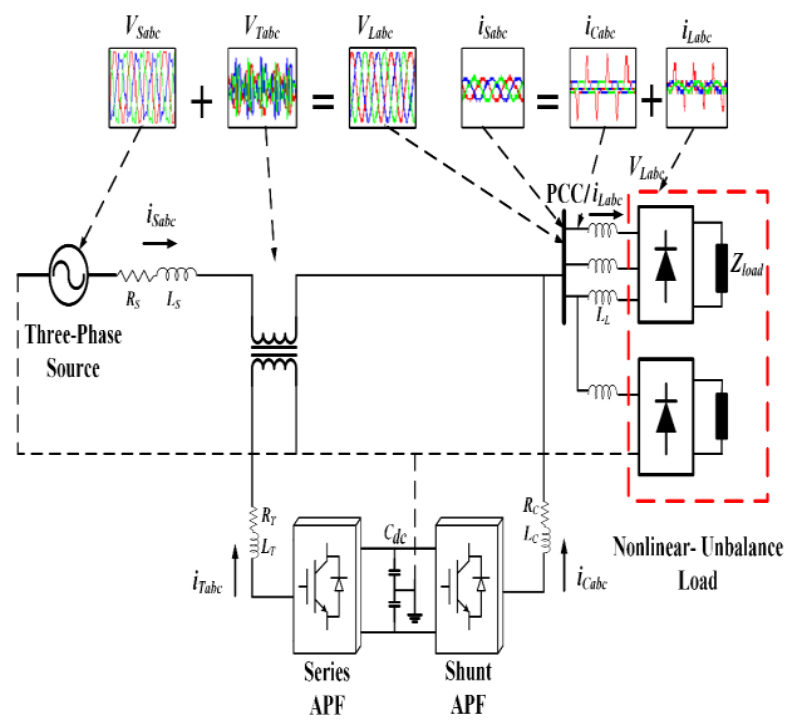

Figure 1. The basic structure of unified power quality conditioner (UPQC).

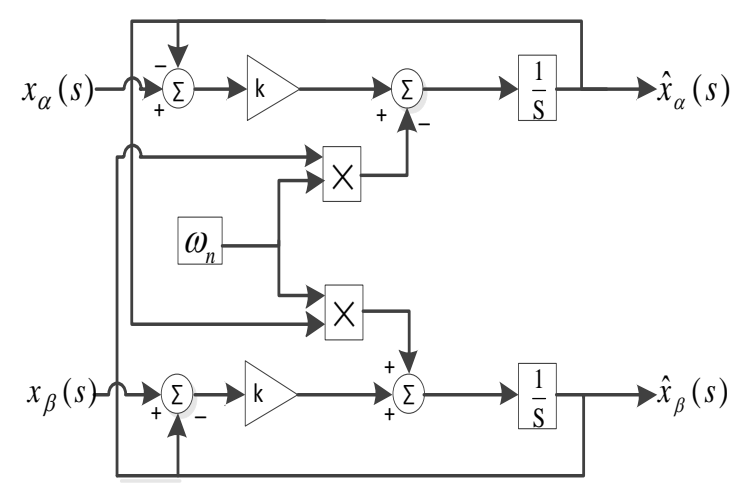

Figure 2. The block diagram of STF.

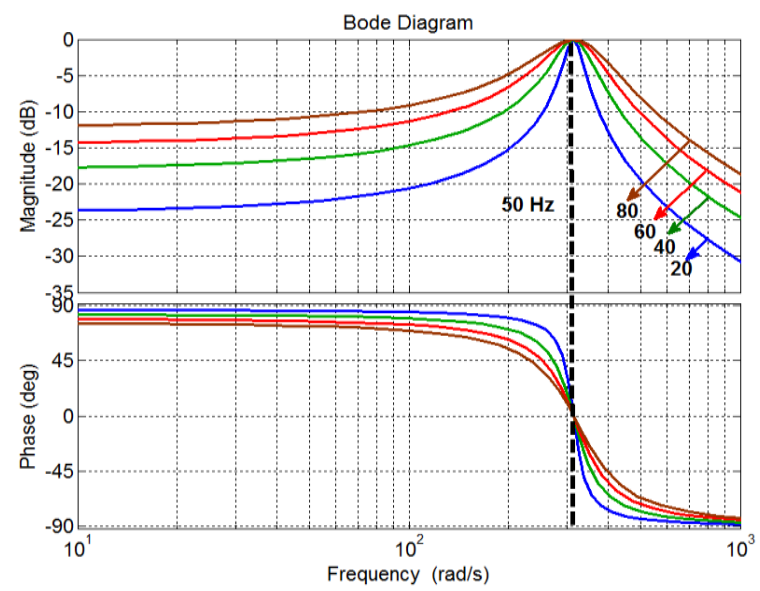

Figure 3. Bode diagram for the STF versus pulsation for different values of the parameter $k(f c=50 H z)$.

\subsection{Reference voltage signal generation of the series APF}

The proposed control method has been used for solving all the problems related to the power quality including source voltage harmonics, unbalanced voltages, voltage sag and swell. In the proposed approach, by using (7), first the measured voltages of source are transferred to the d-q-o coordinates. Under harmonic voltage conditions, instantaneous voltages of source $\left(\mathrm{v}_{\mathrm{sq}}\right.$ and $\mathrm{v}_{\mathrm{sd}}$ ) contain two components; harmonic and mean component, the latter contains the positive sequence. Furthermore, when the voltage unbalance exists, the zero sequence voltage $\left(\mathrm{v}_{\mathrm{so}}\right)$ of source also emerges.

$\left[\begin{array}{l}\mathrm{v}_{\mathrm{S} 0} \\ \mathrm{v}_{\mathrm{Sd}} \\ \mathrm{v}_{\mathrm{Sq}}\end{array}\right]=\sqrt{\frac{2}{3}}\left[\begin{array}{ccc}\frac{1}{\sqrt{2}} & \frac{1}{\sqrt{2}} & \frac{1}{\sqrt{2}} \\ \sin (\omega \mathrm{t}) & \sin \left(\omega \mathrm{t}-\frac{2 \pi}{3}\right) & \sin \left(\omega \mathrm{t}+\frac{2 \pi}{3}\right) \\ \cos (\omega \mathrm{t}) & \cos \left(\omega \mathrm{t}-\frac{2 \pi}{3}\right) & \sin \left(\omega \mathrm{t}+\frac{2 \pi}{3}\right)\end{array}\right]\left[\begin{array}{c}\mathrm{v}_{\mathrm{Sa}} \\ \mathrm{v}_{\mathrm{Sb}} \\ \mathrm{v}_{\mathrm{Sc}}\end{array}\right]$

As it is stated in (8) and (9), the source voltages in d-q-o coordinates contains harmonic and mean components. In order to compensate for harmonic and unbalance voltages, a negative and zero sequence of voltage set to zero and the 
fundamental component of voltage in $\mathrm{d}$ axes $\left(\mathrm{v}_{\mathrm{sd}}\right)$ are separated from harmonic components by the LPF. Therefore, the load reference voltage is obtained by (10):

$$
\mathbf{v}_{\mathrm{Sd}}=\hat{\mathbf{v}}_{\mathrm{Sd}}+\tilde{\mathbf{v}}_{\mathrm{Sd}}
$$

$\mathbf{v}_{\mathrm{Sq}}=\hat{\mathbf{v}}_{\mathrm{Sq}}+\tilde{\mathbf{v}}_{\mathrm{Sq}}$

$\left[\begin{array}{c}v_{\mathrm{La}}^{*} \\ \mathrm{v}_{\mathrm{Lb}}^{*} \\ \mathrm{v}_{\mathrm{LC}}^{*}\end{array}\right]=\sqrt{\frac{2}{3}}\left[\begin{array}{ccc}\frac{1}{\sqrt{2}} & \sin (\omega \mathrm{t}) & \cos (\omega \mathrm{t}) \\ \frac{1}{\sqrt{2}} & \sin \left(\omega \mathrm{t}-\frac{2 \pi}{3}\right) & \cos \left(\omega \mathrm{t}-\frac{2 \pi}{3}\right) \\ \frac{1}{\sqrt{2}} & \cos \left(\omega \mathrm{t}-\frac{2 \pi}{3}\right) & \cos \left(\omega \mathrm{t}+\frac{2 \pi}{3}\right)\end{array}\right]\left[\begin{array}{c}0 \\ \hat{\mathrm{v}}_{\mathrm{Sd}} \\ 0\end{array}\right]$

The three phase reference load voltages $\left(\mathrm{V}_{\text {Labc }}^{*}\right)$ are compared to the distortional voltages of source side $\left(\mathrm{V}_{\text {Sabc }}\right)$ and the errors are processed by the PWM controller and required signals for IGBT switches of the series APF are generated.

The voltage sag or swell compensation may include absorbing/injecting real power from/to supply line. Therefore, real powers of series and shunt APFs must be balanced. In order to make the dc-link voltage fixed, the absorbed and injected real powers by series and shunt APFs must be equal to injected and absorbed powers by shunt APF, respectively [27]. The series APF control is shown in figure 4.

\subsection{Reference current signal generation of the shunt APF}

The shunt APF is used for compensating harmonics, load unbalance and reactive power generated by nonlinear load. The p-q theory is used to control the shunt APF. In this theory, voltages and currents are transferred to $\alpha-\beta-o$ coordinates by (11) and (12):

$\left[\begin{array}{c}i_{\mathrm{S} 0} \\ i_{\mathrm{S} \alpha} \\ i_{\mathrm{S} \beta}\end{array}\right]=\sqrt{\frac{2}{3}}\left[\begin{array}{ccc}\frac{1}{\sqrt{2}} & \frac{1}{\sqrt{2}} & \frac{1}{\sqrt{2}} \\ 1 & -\frac{1}{2} & -\frac{1}{2} \\ 0 & \frac{\sqrt{3}}{2} & -\frac{\sqrt{3}}{2}\end{array}\right]\left[\begin{array}{l}i_{\mathrm{Sa}} \\ i_{\mathrm{Sb}} \\ i_{\mathrm{Sc}}\end{array}\right]$

$\left[\begin{array}{l}\mathbf{v}_{\mathrm{S} 0} \\ \mathbf{v}_{\mathrm{S} \alpha} \\ \mathbf{v}_{\mathrm{S} \beta}\end{array}\right]=\sqrt{\frac{2}{3}}\left[\begin{array}{ccc}\frac{1}{\sqrt{2}} & \frac{1}{\sqrt{2}} & \frac{1}{\sqrt{2}} \\ 1 & -\frac{1}{2} & -\frac{1}{2} \\ 0 & \frac{\sqrt{3}}{2} & -\frac{\sqrt{3}}{2}\end{array}\right]\left[\begin{array}{l}\mathbf{v}_{\mathrm{Sa}} \\ \mathrm{v}_{\mathrm{Sb}} \\ \mathrm{v}_{\mathrm{Sc}}\end{array}\right]$

The current transferred to the Clark's system enter the STF which is set to the fundamental frequency. The STF output currents will be the fundamental components $\left(\hat{i}_{s \alpha}\right.$ and $\left.i_{s \beta}^{\wedge}\right)$ which will contain the fundamental components of active and reactive powers. To fully compensate for the reactive power, the fundamental component of reactive power obtained from (13) must be subtracted as a current component from current fundamental components.

Considering the switching loss $\left(\mathrm{P}_{\text {Loss }}\right)$, voltage fluctuation would be a good index showing that these fluctuations could be converted into a current by using a proportional-integral (PI) controller. This current must be injected into a main axis. Hence, For DC voltage regulation, voltage of dc-link is compared with reference voltage $\left(\mathrm{V}^{*}{ }_{\mathrm{DC}}\right)$, and then is injected to into the main axis by PI and it doesn't need any external supply.

On the other hand, when the load is unbalanced, there will be current in neutral wire. the total power of zero sequence component will be obtained from (14). To decrease the neutral current, the total zero sequence power must be supplied by shunt APF and this index must also be injected into main axis. As it is stated in (15), if it is needed to fully compensate for both the zero sequence component and reactive power, $i_{s \alpha}^{\prime}$ and $\mathrm{i}_{\mathrm{s} \beta}{ }^{\prime}$ are the reference injected currents which must be injected into $\alpha-\beta$ axes. As it is stated in (16) and (17), by injecting these currents into $\alpha-\beta$ axes, the reference currents $i^{*}{ }_{s \alpha}$ and $i_{s \beta}^{*}$ for shunt APF are obtained. Then, the reference currents in abc coordinates are calculated by (18).

$$
\begin{aligned}
& \hat{\mathbf{q}}=\hat{\mathbf{i}}_{\beta} \hat{\mathbf{v}}_{S \alpha}-\hat{\mathbf{i}}_{\alpha} \hat{\mathbf{v}}_{S \beta} \\
& p_{0}=v_{\text {So }} i_{\text {So }} \\
& {\left[\begin{array}{c}
\mathbf{i}_{\mathrm{S} \alpha}^{\prime} \\
\mathbf{i}_{\mathrm{S} \beta}^{\prime}
\end{array}\right]=\frac{1}{\hat{\mathbf{v}}_{\mathrm{S} a}^{2}+\hat{\mathbf{v}}_{\mathrm{S} \beta}^{2}}\left[\begin{array}{cc}
\hat{\mathbf{v}}_{\mathrm{S} a} & -\hat{\mathbf{v}}_{\mathrm{S} \beta} \\
\hat{\mathbf{v}}_{\mathrm{S} \beta} & \hat{\mathbf{v}}_{\mathrm{S} a}
\end{array}\right]\left[\begin{array}{c}
\mathbf{p}_{\mathrm{Loss}}+\mathbf{p}_{0} \\
-\hat{\mathbf{q}}
\end{array}\right]} \\
& \mathbf{i}_{\mathrm{S} \alpha}^{*}=\hat{\mathbf{i}}_{\mathrm{S} \alpha}+\mathbf{i}_{\mathrm{S} \alpha}^{\prime} \\
& \mathbf{i}_{\mathrm{S} \beta}^{*}=\hat{\mathbf{i}}_{\mathrm{S} \beta}+\mathbf{i}_{\mathrm{S} \beta}^{\prime} \\
& {\left[\begin{array}{l}
i_{\mathrm{Sa}}^{*} \\
i_{\mathrm{Sb}}^{*} \\
i_{\mathrm{Sc}}^{*}
\end{array}\right]=\sqrt{\frac{2}{3}}\left[\begin{array}{cc}
1 & 0 \\
-\frac{1}{2} & \frac{\sqrt{3}}{2} \\
-\frac{1}{2} & \frac{-\sqrt{3}}{2}
\end{array}\right]\left[\begin{array}{l}
i_{\mathrm{S} a}^{*} \\
i_{\mathrm{S} \beta}^{*}
\end{array}\right]}
\end{aligned}
$$

The reference currents, $i^{*}{ }_{s a}, i_{s b}^{*}$ and $i_{s c}^{*}$ are calculated to compensate neutral currents, reactive and harmonic currents in the load. These reference source currents are compared to measured currents of the source and errors resulted from this comparison are received by a hysteresis band controller to produce required switching signals of shunt APF. The shunt APF control is shown in figure 4. 


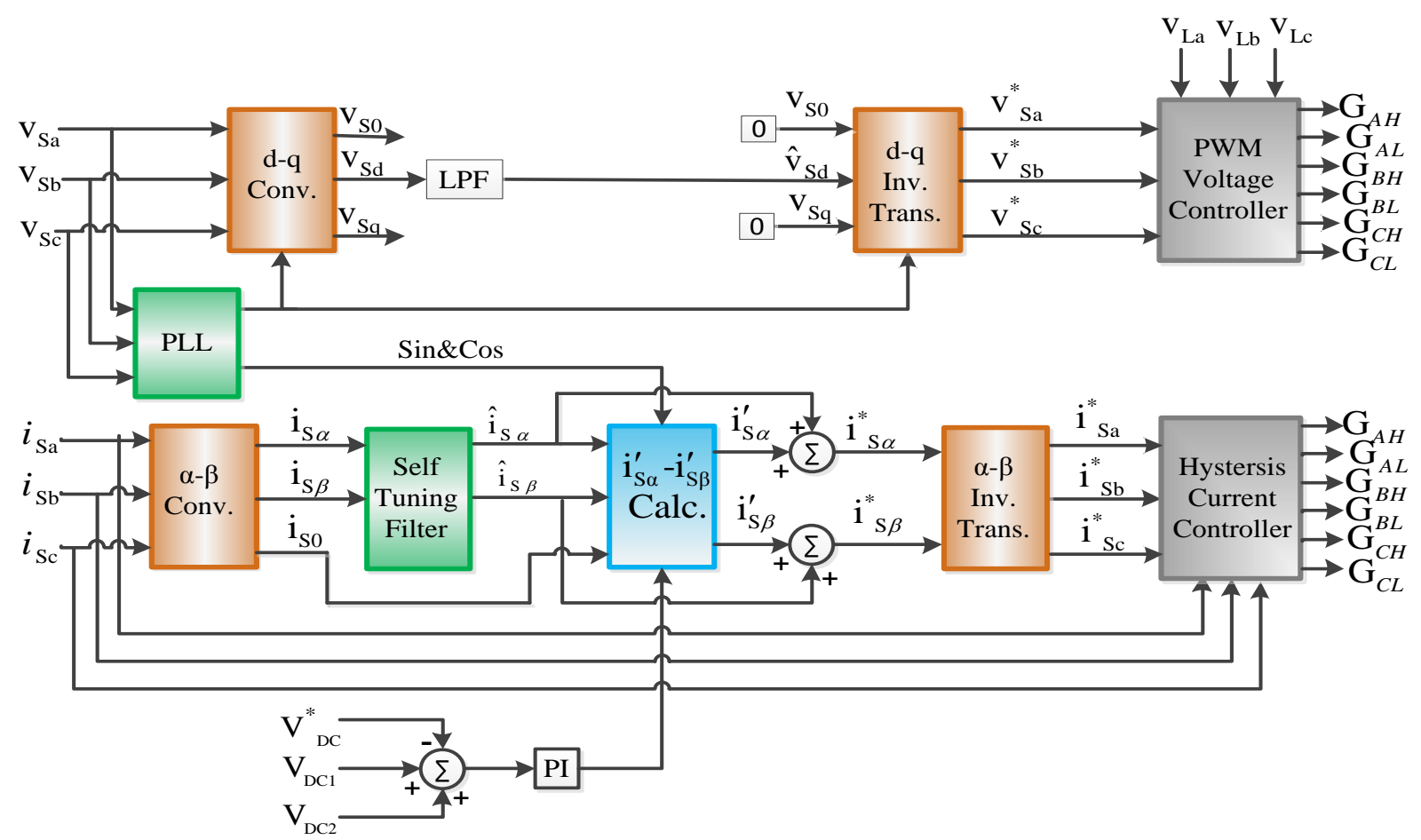

Figure 4. The block diagram of proposed control method for UPQC.

\section{Simulation results}

In this study, the proposed control method for UPQC which is used for compensating distortional and unbalanced load currents under the conditions of distortional and unbalanced source voltages are evaluated by MATLAB software. The load used in simulations is a combination of a three-phase rectifier load and a single-phase rectifier load. The single-phase rectifier load is used to create load unbalance in phase 'a'. Also, the source voltage contains odd harmonics up to the order of 17. Furthermore, the third harmonic and its multiples are not considered in simulations, because the third harmonic and its multiples will be compensated by the connections of transformers and often there is no need to compensate for them by the series APF. Passive filters with $R$ and $C$ are used to remove the switching ripples in voltage and current waveforms. The values of simulated parameters are given in table 1.

4.1. The performance of UPQC in load balancing, power factor correction and current and voltage harmonics compensation

The responses of UPQC in load balancing, power factor correction and current and voltage harmonics compensation are shown in figure 5. Figure 5(a) shows the harmonic voltages before compensation. It could be seen from figure 5(c) that by injecting compensating for voltage into system, the series APF of UPQC removes source voltage harmonics and creates sinusoidal voltages for the load. Voltages injected by the series APF are shown in figure 5(b). As voltage harmonics is removed by the series APF, load voltage THD decreases from $11.25 \%$ to $1.47 \%$. Voltage harmonics spectrums before and after compensation are shown in figure 6(a) and figure 6(b), respectively. On the other hand, figure 5(d) shows the load harmonic and unbalanced current before compensation. It could be seen from figure 5(f) that by injecting compensating currents for system, the shunt APF makes the source current sinusoidal and balanced and decreases source current THD from $28.27 \%$ to $2.36 \%$. The currents injected by shunt APF into the network are shown in figure 5(e). Also, the current harmonic spectrum of phase ' $a$ ' of the source before and after compensation, are shown in figure 6(c) and figure 6(d), respectively. It could be seen from figure $5(\mathrm{~g})$ that the current through neutral wire before compensation is equal to $26.6 \mathrm{~A}$. When the neutral compensating for current is injected by the shunt APF, the neutral current of source decreases to zero. The neutral compensating for current injected by shunt APF and source neutral current are shown in figure 5(h) and figure 5(i), respectively. As UPQC enters the circuit, the whole reactive power of load is supplied by shunt APF and voltages and currents of source become in phase and the load just derives reactive power from source. Figure 5(k) shows the reactive power 
derived from the source which has an amplitude equal to zero.

Table 1. System parameters [19].

\begin{tabular}{|c|c|c|c|}
\hline & Parameters & & Value \\
\hline \multirow{2}{*}{ Source } & Voltage & $\mathrm{V}_{\text {Sabc }}$ & $380 \mathrm{~V}$ \\
\hline & Frequency & $\mathrm{f}$ & $50 \mathrm{~Hz}$ \\
\hline \multirow{6}{*}{ Load } & 3-Phase ac Line Inductance & $\mathrm{L}_{\mathrm{abc}}$ & $2 \mathrm{mH}$ \\
\hline & 1-Phase ac Line Inductance & $\mathrm{L}_{\mathrm{La} 1}$ & $1 \mathrm{mH}$ \\
\hline & 3-Phase dc Inductance & $L_{d c 3}$ & $10 \mathrm{mH}$ \\
\hline & 3-Phase dc Resistor & $\mathrm{R}_{\mathrm{dc} 3}$ & $100 \Omega$ \\
\hline & 1-Phase dc Resistor & $\mathrm{R}_{\mathrm{dc} 1}$ & $50 \Omega$ \\
\hline & 1-Phase dc Capacitor & $\mathrm{C}_{\mathrm{dc} 1}$ & $240 \mu \mathrm{f}$ \\
\hline \multirow{2}{*}{ dc-link } & Voltage & $\mathrm{V}_{d c}$ & $700 \mathrm{~V}$ \\
\hline & Capacitor & $\mathrm{C}_{1} / \mathrm{C}_{2}$ & $2200 \mu \mathrm{F}$ \\
\hline \multirow{4}{*}{$\begin{array}{l}\text { Shunt } \\
\text { APF }\end{array}$} & Ac Line Inductance & $\mathrm{L}_{\mathrm{Cabc}}$ & $1 \mathrm{mH}$ \\
\hline & Filter Resistor & $R_{C a b c}$ & $5 \Omega$ \\
\hline & Filter Capacitor & $\mathrm{C}_{\text {Cabc }}$ & $4.7 \mu \mathrm{F}$ \\
\hline & Hysteresis Band & $\mathrm{h}$ & $0.5 \mathrm{~A}$ \\
\hline \multirow{4}{*}{$\begin{array}{l}\text { Series } \\
\text { APF }\end{array}$} & Ac Line Inductance & $\mathrm{L}_{\mathrm{Sabc}}$ & $0.6 \mathrm{mH}$ \\
\hline & Filter Resistor & $\mathrm{R}_{\mathrm{Sabc}}$ & $5 \Omega$ \\
\hline & Filter Capacitor & $\mathrm{C}_{\text {Sabc }}$ & $26 \mu \mathrm{F}$ \\
\hline & Switching Frequency & $\mathrm{f}_{\text {PWM }}$ & $15 \mathrm{kH}$ \\
\hline STF & Factor k In STF Block & $\mathrm{k}$ & 60 \\
\hline
\end{tabular}

\subsection{Performance of UPQC during a sudden} increase of load

In this section, to investigate the dynamic response of UPQC and to see how it enters the circuit, first it is assumed that UPQC is not in the circuit. As it could be seen from figure 7 (a) and figure 7(c), source contains unbalanced and harmonic voltages and load derives unbalanced and harmonic currents from the source. At $\mathrm{t}=0.1 \mathrm{~s}$, the UPQC enters the circuit and shunt and series APFs start the compensation. Figure 7 (b) shows that when UPQC enters the circuit, series APF immediately injects compensating voltages into the network and makes the load voltages sinusoidal.

Also, figure 7(d) shows the currents generated by shunt APF which makes the currents derive from the network balanced and sinusoidal. The performance of UPQC in compensating for the neutral current of source and load reactive power is shown in figure 7(f) and figure 7(h), respectively.
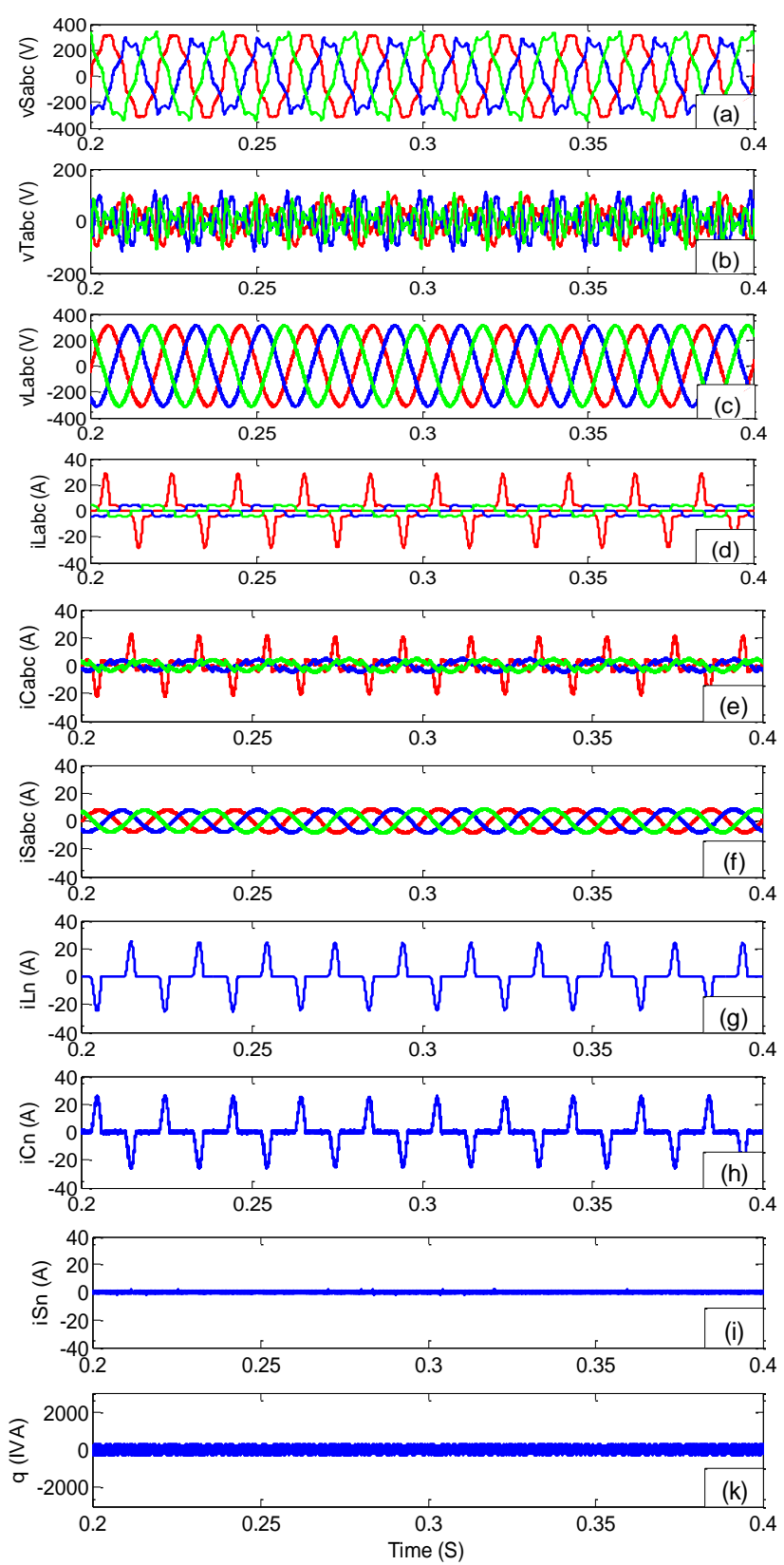

Figure 5. Simulation results for the proposed control approach for: (a) source distortional voltages, (b) voltages injected by transformer (c) load voltages (d) unbalanced and nonlinear load currents (e) currents injected by compensator (f) source currents (g) load neutral current (i) neutral current injected by compensator (h) instantaneous reactive power.

In order to show the UPQC performance during a sudden change in the load, when system is operating, the load is suddenly increased at $\mathrm{t}=0.2 \mathrm{~s}$. As it is shown in figure 7 , in addition to compensating for load unbalance, supplying reactive power and compensating for harmonics, the UPQC controller gets a new static state after the load change. 

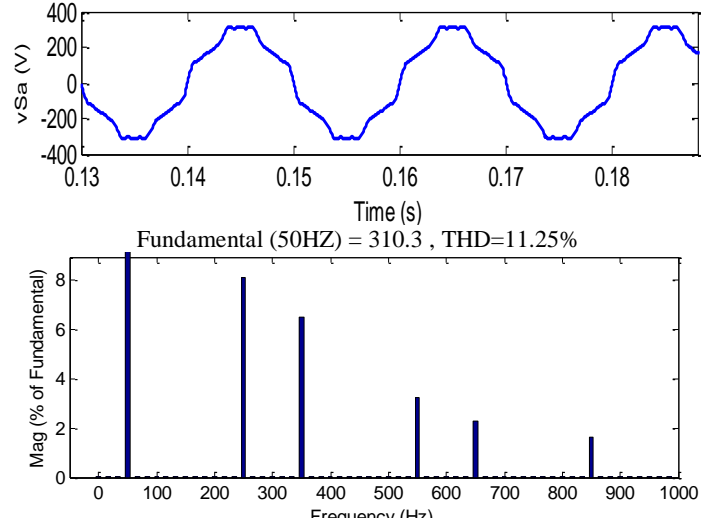

Figure 6(a). Load voltage and its harmonic spectrum before compensation.
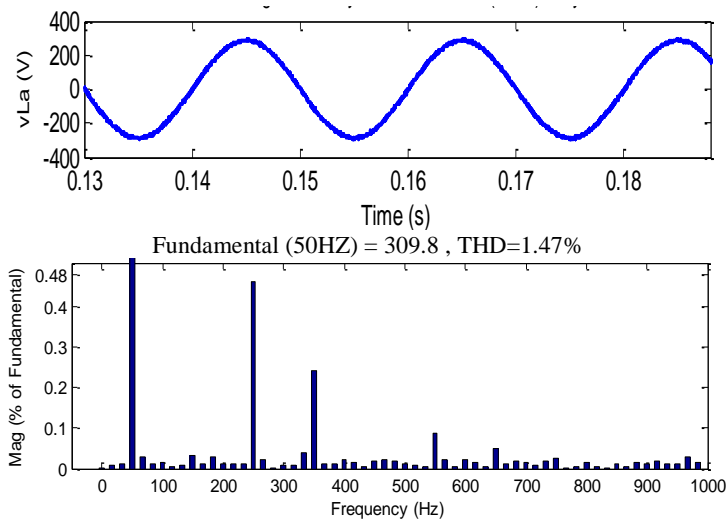

Figure 6(b). Load voltage and its harmonic spectrum after compensation.
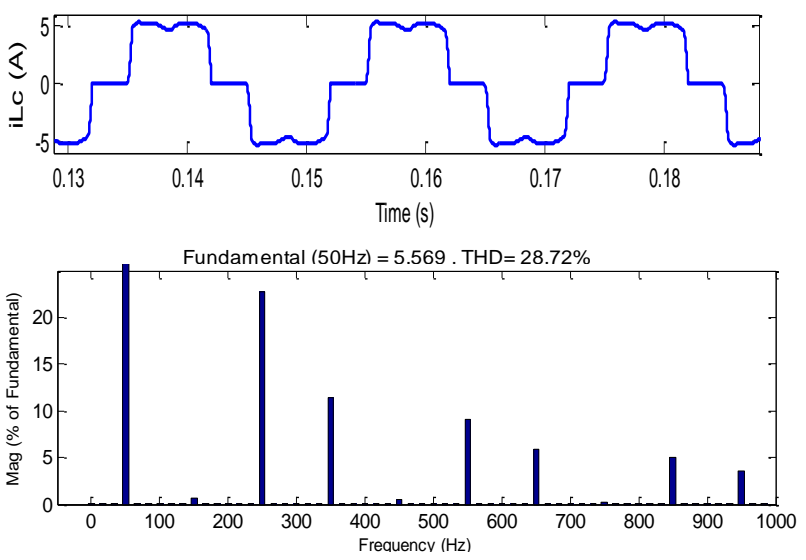

Figure 6(c). Load current and its harmonic spectrum before compensation.
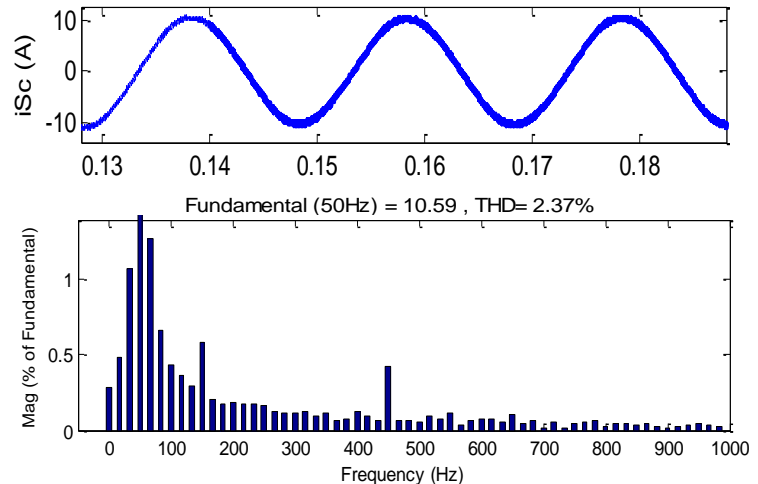

Figure 6(d). Load current and its harmonic spectrum after compensation.
Furthermore, figure 7(i) shows that a slight change in dc-link voltage occurs at the moment that the load change $(0.2 \mathrm{~s})$ which is immediately controlled by the dc-link voltage controller and the dc-link voltage returns to its previous value.
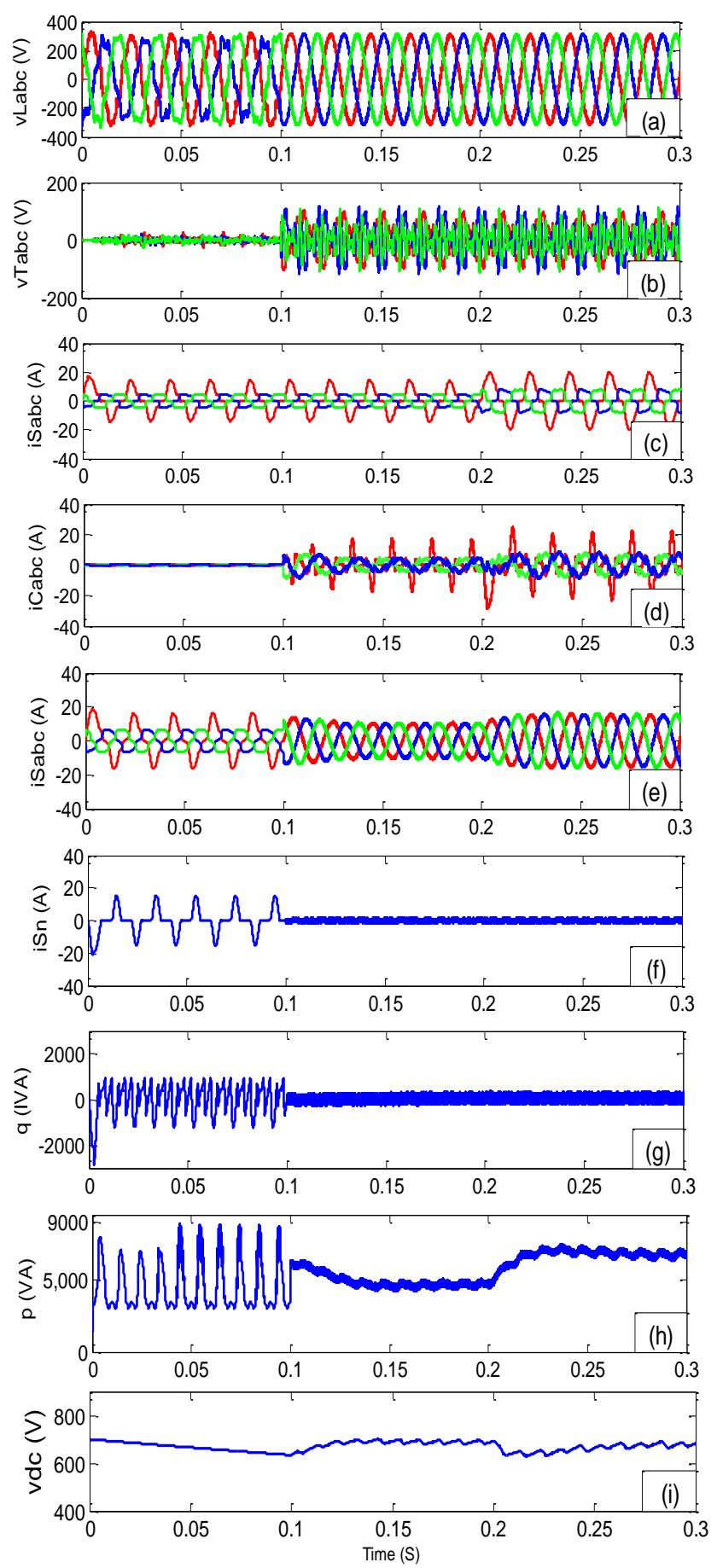

Figure 7. The results of UPQC performance while operating. (a) load voltages, (b) voltages injected by the series transformers (c) load currents (d) source currents (e) the injected compensating currents (f) source neutral current (g) instantaneous reactive power (h) instantaneous active power (i) dc link voltage. 


\subsection{Comparison to the convention methods}

Conventional techniques published so far in the literature have more computational burden. On the other hand, the proposed method is a simple approach for effectively compensating current and voltage harmonics, reactive power and load balancing. Other advantages of this approach is the reduction of number of current and voltage measurements for controlling the shunt and series APFs. In the proposed method, to control the shunt APF, we just need to measure the source current whereas in conventional techniques, it is necessary to measure the currents of load, source and shunt APF. In the proposed control method, it is not necessary to measure neither the currents of shunt APF or the voltages of series APF which have fast variations. In order to compare the proposed approach with conventional p-q method, the results obtained from both these techniques are compared in table 2.

Table 2. \% THD of the supply currents and load voltages.

\begin{tabular}{cccc}
\hline $\begin{array}{c}\text { Supply } \\
\text { currents/load } \\
\text { voltage }\end{array}$ & $\begin{array}{c}\text { Without } \\
\text { UPQC }\end{array}$ & $\begin{array}{c}\text { UPQC with } \\
\text { proposed } \\
\text { method }\end{array}$ & $\begin{array}{c}\text { UPQC with } \\
\text { conventional } \\
\text { p-q method }\end{array}$ \\
\hline $\begin{array}{c}\text { \%THD in } \\
\text { current in } \\
\text { Phase a }\end{array}$ & $28.72 \%$ & $2.36 \%$ & $3.04 \%$ \\
\hline $\begin{array}{c}\% \text { THD in load } \\
\text { voltage }\end{array}$ & $11.25 \%$ & $1.47 \%$ & $2.23 \%$ \\
\hline
\end{tabular}

The simulation results obtained by using conventional p-q method are shown in figure 8 . Figure 8(a) shows the source harmonic voltages before compensation. It could be seen from figure 8 (c) that by injecting compensating voltages into system, the series APF of UPQC generates sinusoidal load voltages and decreases the load voltage THD from $11.25 \%$ to $2.23 \%$ whereas in the proposed control method, the load voltage THD is decreased from $11.25 \%$ to $1.47 \%$. The voltages injected by the series APF are shown in figure 6(b). On the other hand, figure 8(f) shows that, by injecting compensating currents for network, the UPQC shunt APF compensates load unbalance and load current harmonics and also decreases the source current THD from $28.72 \%$ to $3.04 \%$, whereas in the proposed control method, source current THD is decreased from $28.72 \%$ to $2.23 \%$.

The load harmonic and unbalanced currents and shunt APF injected currents are shown in figure 8(d) and figure 8(e), respectively. Figure 8(i) shows that the source neutral current is decreased to zero by the shunt APF of UPQC. It could be seen from figure $8(\mathrm{k})$ that reactive power is fully compensated by shunt APF. Simulation results show that the proposed control technique outperforms conventional p-q control theory.
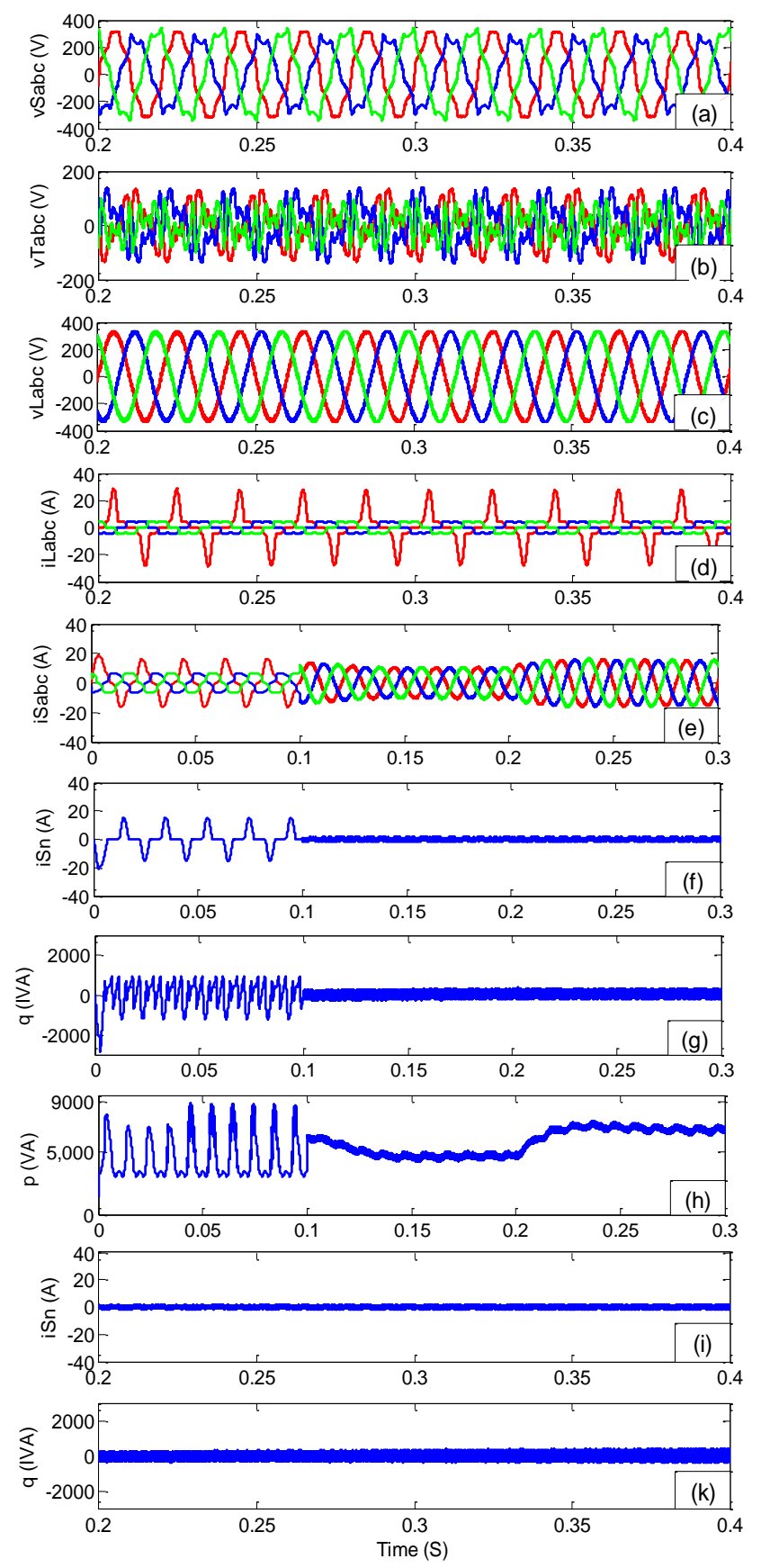

Figure 8. Simulation results for conventional p-q method: (a) distortional unbalanced voltages of the source (b) voltages injected by the transformer (c) load voltages (d) unbalanced and nonlinear load currents (e) currents injected by the compensator (f) source currents (g) load neutral current (h) neutral current injected by compensator (i) source neutral current (h) instantaneous reactive power.

\section{Conclusion}

In this paper, the performance of the proposed control method for a three-phase four wire UPQC was investigated. Simulation results show the capability of proposed control approach in dealing 
with the problems of power quality such as load balancing, load reactive power compensation, and current and voltage harmonics compensation under voltage unbalance conditions. In the proposed control method, to control the shunt APF, we just need to measure source current while in conventional methods currents of load, source and shunt APF must be measured. Therefore, the number of current measurements is decreased in the proposed approach. Simulation results show that under conditions of unbalanced and nonlinear load current, this method not only decreases the effects of load distortion and unbalance in the power system, but also improves the power factor. Meanwhile, whenever the source voltages are distortional and unbalanced, the series APF provides sinusoidal voltages for loads. Also, in this research, it is shown that the UPQC simultaneously compensates voltage and current problems and it has the best compensation features even during the emergence of unbalanced components in the three-phase four-wire electrical systems. Simulation results reveal that the proposed control technique has better compensation performance than conventional $\mathrm{p}-\mathrm{q}$ control theory.

\section{References}

[1] Gunther, E. W. \& Mehta, H. (1995). A Survey of Distribution System Power Quality. IEEE Transactions on Power Delivery, vol. 10, no. 1, pp. 322-329.

[2] Gun Lee, G., Albu, M. M. \& Heydt, G. T. (2004). A Power Quality Index Based on Equipment Sensitivity, Cost and Network Vulnerability. IEEE Transactions on Power Delivery. vol. 19, no. 3, pp. 1504-1510.

[3] Ewald, F. \& Mausoum, M. A. S. (2008). Power Quality in Power Systems and Electrical Machines. Elsevier, Academic Press, London, UK.

[4] Singh, B., Al-Haddad, K. \& Chandra, A. (1999). A Review of Active Filters for Power Quality Improvement. IEEE Transactions on Industrial Electronics, vol. 46, no. 5, pp. 960-971.

[5] Akagi, H. (1996). New Trends in Active Filters for Power Conditioning. IEEE Transactions on Industry Applications, vol. 32, no. 6, pp. 1312-1322.

[6] Fang, Z., Akagi, H. \& Nabae, A. (1990). A New Approach to Harmonic Compensation in Power Systems-a Combined System of Shunt Passive and Series Active Filters. IEEE Transactions on Industry Applications, vol. 26, no. 6, pp. 983-990.

[7] Fujita, H. \& Akagi, H. (1998). The Unified Power Quality Conditioner: the Integration of Series and Shunt-Active Filters. IEEE Transactions on Power Electronics, vol. 13, no. 2, pp. 315-322.

[7] Senand, K. K. \& Stacey, E. J. (1998). UPFC-
Unified Power Flow Controller: Theory, Modeling, and Applications. IEEE Transactions on Power Delivery. vol. 13 , no. 4 , pp. 1453- 1460.

[9] Han, B., Bae, B., Kim, H. \& Baek, S. (2006). Combined Operation of Unified Power-Quality Conditioner with Distributed Generation. IEEE Transactions on Power Delivery, vol. 21, no. 1, pp. 330 -338 .

[10] Zhili, T., Xun, L., Jian, C., Yong, K. \& Shanxu, D. (2006). A Direct Control Strategy for UPQC in ThreePhase Four-Wire System. 5th International Conference on Power Electronics and Motion Control. Shanghai, China, 2006.

[11] Khadkikar, V. \& Chandra, A. (2009). A Novel Structure for Three-Phase Four-Wire Distribution System Utilizing Unified Power Quality Conditioner (UPQC). IEEE Transactions on Industry Applications, vol. 45 , no. 5 , pp. 1897- 1902.

[12] Xun, L., Guorong, Z., Shanxu, D. \& Jian Chen, C. (2007). Control Scheme for Three-Phase Four-Wire UPQC in a Three-Phase Stationary Frame. Annual Conference of the IEEE on Industrial Electronics Society. Taipei, Taiwan, 2007.

[13] Ghosh, A., Jindal, A. K. \& Joshi, A. (2004). A Unified Power Quality Conditioner for Voltage Regulation of Critical Load Bus. IEEE Power Engineering Society General Meeting, 2004.

[14] Bhuvaneswari, G. \& Nair, M. G. (2008). Design, Simulation, and Analog Circuit Implementation of a Three-Phase Shunt Active Filter Usingthe ICos $\Phi$ Algorithm. IEEE Transactions on Power Delivery, vol.23, no.2, pp.1222- 1235 .

[15] Yash, P., Swarup, A. \& Singh, B. (2012). A Novel Control Strategy of Three-phase, Four-wire UPQC for Power Quality Improvement, Journal of Electrical Engineering \& Technology, vol. 1, no. 1, pp. 1- 8.

[16] Teke, A., Saribulut, L. \& Tumay, M. (2011). A Novel Reference Signal Generation Method for PowerQuality Improvement of Unified Power-Quality Conditioner, IEEE Transactions Power Delivery, vol.26, no. 4, pp.2205- 2214.

[17] Abardeh, M. H \& Ghazi, R. (2010). A New Reference Waveform Estimation Strategy for Unified Power Quality Conditioner (UPQC). IEEE International Energy Conference \& Exhibition. Manama, Bahrain,2010.

[18] Guozhu, C., Yang, C. \& Smedley, K. M. (2004). Three-Phase Four-Leg Active Power Quality Conditioner Without References Calculation. Nineteenth Annual IEEE Applied Power Electronics Conference and Exposition, 2004.

[19] Kesler, M. \& Ozdemir, E. (2011). SynchronousReference-Frame-Based Control Method for UPQC under Unbalanced \& Distorted Load Conditions. IEEE Transactions on Industrial Electronics, vol. 58, no.9, pp. 3967- 3975. 
[20] Teke; A., Meral, M.E., Cuma, M. U., Tumay, M. \& Bayindir, K. C. (2013). OPEN Unified Power Quality Conditioner with Control Based on Enhanced Phase Locked Loop. Generation, Transmission and Distribution, vol. 7, no. 3, pp. 254- 264.

[21] Viji, A. J. \& Sudhakaran, M. (2012). Generalized UPQC System with an Improved Control Method Under Distorted and Unbalanced Load Conditions. International Conference on Computing, Electronics and Electrical Technologies. Kumaracoil, 2012.

[22] Da Silva, C. H., Pereira, R. R., Da Silva, L. E. B., Lambert-Torres, G., Bose, B. K. \& Ahn, S. U. (2010). A Digital PLL Scheme for Three-Phase System Using Modified Synchronous Reference Frame. IEEE Transactions on Industrial Electronics, vol. 57, no. 11, pp. 3814- 3821.

[23] Correa, J. M., Farret, F. A. \& Simoes, M. G. (2005). Application of a Modified Single-Phase P-Q Theory in the Control of Shunt and Series Active Filters in a $400 \mathrm{~Hz}$ Microgrid. 36th IEEE Power Electronics Specialists Conference, Recife, Brazil, 2005.

[24] Da Silva, S. A. O., Barriviera, R., Modesto, R. A, Kaster, M. \& Goedtel, A. (2011). Single-Phase Power Quality Conditioners with Series-Parallel Filtering Capabilities, IEEE International Symposium on Industrial Electronics. Gdansk, 2011.

[25] Viji, A. J. \& Sudhakaran, M. (2012). Flexible 3P4W System Using UPQC with Combination of SRF and P-Q Theory Based Control Strategy. 22nd Australasian Universities Power Engineering Conference. Bali,2012.
[26] Kesler, M. \& Ozdemir, E. (2010). A Novel Control Method for Unified Power Quality Conditioner (UPQC) Under Non-Ideal Mains Voltage and Unbalanced Load Conditions. 25th Annual IEEE Applied Power Electronics Conference and Exposition. Palm Springs, CA, 2010.

[27] Akagi, H., Watanabe, E. \& Aredes, M. (2007). Instantaneous Power Theory and Applications to Power Conditionin. New Jersey, John Wiley \& Sons.

[28] Kinhal, V. G, Agarwal, P. \& Gupta, H. (2011). Performance Investigation of Neural-Network-Based Unified Power-Quality Conditioner. IEEE Transactions on Power Delivery, vol. 26, no. 1, pp. 431- 437.

[29] Dinesh, L., Srinivasa, S. \& Mallikarjuna Rao, N. (2012). Simulation of Unified Power Quality Conditioner for Power Quality Improvement Using Fuzzy Logic and Neural Networks. Innovative Systems Design and Engineering, pp.3, no. 3, pp. 36- 47.

[30] Song, H., Park, H. \& Nam, K. (1999). An Instantaneous Phase Angle Detection Algorithm Under Unbalanced Line Voltage Condition. 30th Annual IEEE Power Electronics Specialists Conference, Charleston, SC. 1999.

[31] Abdusalam, M., Poure, P., Karimi, S. \& Saadate, S. (2009). New Digital Reference Current Generation for Shunt Active Power Filter Under Distorted Voltage Conditions. Electric Power Systems Research, vol. 79, no. 10 , pp. $759-765$. 
بهبود عملكرد UPQC تحت شرايط نامتعادلى و اعوجاجى بار: يك روش جديد

رضا غنىزاده" و محمود عباديان

دانشكده مهيندسى برق و كامييوتر، دانشكًاه بير جند، بير جند، ايران.

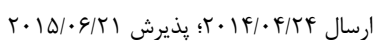

جكيده:

اين مقاله يك روش كنترل جديد براى بهبود دهنده يكيارجه كيفيت توان (UPQC) سهفاز جهارسيمه به منظور مشكلات كيفيت توان، تحست شـايط

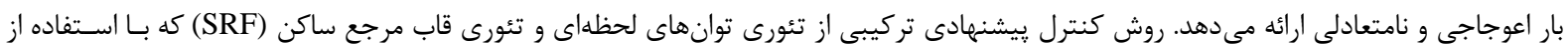

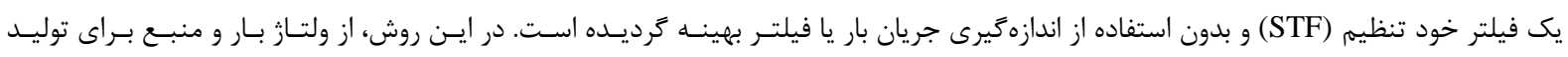

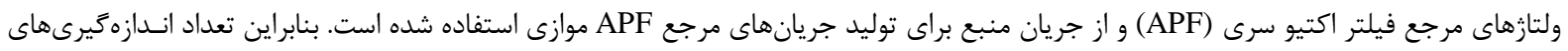

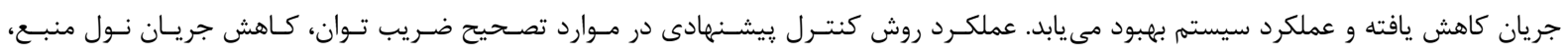

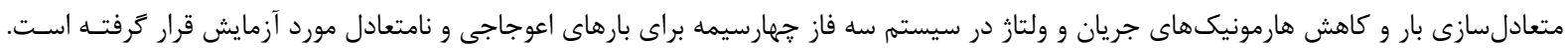

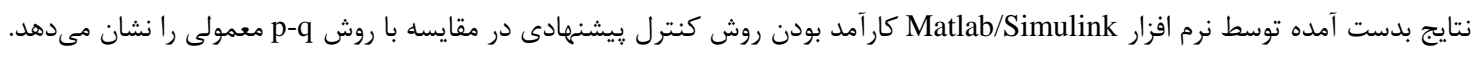
كلمات كليدى: كيفيت توان، بهبود دهنده يكيارجه كيفيت توان، كاهش هارمونيكـهاى ولتار، كـاهش هارمونيكهـاى جريـان، كـاهش جريـان نـول 